\title{
Selection of technology for the low calorific synthetic gas combustion in the gas turbine combustion chamber
}

\author{
Prokopy Filippov", Evgeny Levin, and Alexander Ryzhkov \\ Federal State Autonomous Educational Institution of Higher Education «Ural Federal University \\ named after the first President of Russia B.N. Yeltsin», 620002, 19 Mira street, Ekaterinburg, Russia
}

\begin{abstract}
The leading gas turbines manufacturers are developing the technologies of the environmental friendly combustion of industrial and synthetic gases of low calorific values. In this case they are faced with critical problems concerning combustion stability assurance and the necessity of the gas turbines significant modernization due to the differences between the low calorific and natural gases. The numerical simulation results of the low calorific value synthetic gas combustion in the combustion chamber by means of different technologies are considered in the paper.
\end{abstract}

\section{Introduction}

During development of the combined cycle power plant (CCPP) operated on the synthetic gas it is required to consider the significant difference between the fuel gas and the natural gas properties such as the calorific value, the Wobbe Index, the flame propagation rate as well as the presence of different pollutants. For steady combustion and CCPP cost-effective operation assurance the changes in the standard gas turbine structure and the CCPP scheme can be required [1]. The greater the differences between the fuel gas and the natural gas properties, the greater the modernization depth. In this case the leading manufacturers of the synthetic gas turbine often follow the path of the fuel gases unification by hydrodynamic, thermodynamic and kinetic characteristics by means of the gases dilution or enrichment, and during the synthetic gas combustion scheme development the thermodynamic performance is associated with the corresponding kinetic diagram providing the achievement of the technological and environmental indexes of the process.

However, in case of the air gasification, where the gas calorific value is approximately $3.5 \mathrm{MJ} / \mathrm{m}^{3}$, the applied combustion technology is inoperative, and consequently the additional measures for the synthetic gas correction with the purpose of the calorific value increase should be taken or another combustion technique development is required [2]. The low calorific synthetic gas combustion without the enrichment procedures is considered below.

*Corresponding author: fps_proxi@mail.ru 
On the basis of analysis of the most efficient combustion chambers of the gas turbines operated on the synthetic gases applied at the IGCC, the analog was found and the numerical variation studies of the gas turbine combustion chamber with the power of 300 MW were performed with consideration of the regulatory compliance in the field of the NOx emissions.

\section{Selection of the gas turbine combustion chamber design for the synthetic gas combustion}

For selection of the optimal gas turbine combustion chamber design the numerical simulation of the operation of combustion chamber of three types (Siemens, GE и MHPS) was performed on the low calorific value fuel gases, obtained after correction of the oxygen gasification gases and blast-furnace gases. The gas fuel combustion model was selected among the following four models being most widely used in CFD software packages: the Eddy Dissipation (ED) model, the Finite Rate Chemistry model (FRC), the integrated model Eddy Dissipation/Finite Rate Chemistry (ED/FRC) and the Laminar Flamelet model (LF). Model selection was performed on the basis of comparison of the calculated data, obtained by means of the models, with the experimental data [3], which is widely used for verification of different models $[4,5]$. The calculation results, obtained in the CFD software package with the use of the ED/FRC model, were the closest to the experimental data along the whole combustion chamber length. Therefore the ED/FRC model was used as the gas fuel combustion model.

For the combustion chamber operation simulation the MHPS type combustion chamber was used as the analog which provided the permissible temperature non-uniformities and low emissions of nitrogen oxides $\left(19.02 \mathrm{ppm}=24.73 \mathrm{mg} / \mathrm{nm}^{3}\right)$ and $\mathrm{CO}(0.8 \mathrm{ppm}=$ $\left.1 \mathrm{mg} / \mathrm{nm}^{3}\right)$.

\section{Determination of the low calorific value gases combustion technique}

The NOx emissions during the synthetic gas combustion in the gas turbine combustion chamber depends on the temperature level and temperatures distribution, the local excess air factors, the fuel composition and the calorific value and the combustion products residence time in combustion area.

The impact of the fuel gas characteristics and the temperature regimes during combustion on the NOx emissions was studied in the present paper with the use of the numerical simulation methods with the purpose of determination of the optimal conditions for the low calorific synthetic gas combustion in the gas turbine.

The following temperature regimes of the synthetic gases combustion in the gas turbine can be distinguished:

1) the cold gas $\left(100-180^{\circ} \mathrm{C}\right)$ combustion in the cycle air $\left(400-500^{\circ} \mathrm{C}\right)$. Combustion of the reference gas turbine fuel (natural gas) by the present scheme within the range of $\alpha=1-3$ provides the environmental friendly operation modes of the modern gas turbines of the temperature class $1300-1400^{\circ} \mathrm{C}$. The synthetic gases with the unified calorific value and the high hydrogen concentration $\mathrm{H}_{2}>20 \%$ are combusted in the gas turbines of the temperature class $1100-1300^{\circ} \mathrm{C}$ in a similar way.

2) the hot gas $\left(300-500^{\circ} \mathrm{C}\right)$ combustion in the cycle air $\left(400-500^{\circ} \mathrm{C}\right)$. At the present time it is the basic method for the synthetic gases combustion in the gas turbine of the temperature class $1100-1400^{\circ} \mathrm{C}$. This method is used for the oxygen and air blown integrated gasification combined cycles (IGCC) systems and also for industrial (blast- 
furnace) gases combustion. The gas composition unification by the Wobbe Index, the calorific value and the hydrogen composition is performed in advance. It is the future technology for the IGCC with the hot gas treatment system.

$3)$ the hot gas $\left(300-500^{\circ} \mathrm{C}\right)$ combustion in the high-heat $\left(900-1000^{\circ} \mathrm{C}\right)$ cycle air. In case of the moderately low heat of the fuel gas (up to $500^{\circ} \mathrm{C}$ ) the low calorific gases combustion temperatures become entirely sufficient for the modern gas turbines of the temperature class $1300-1400^{\circ} \mathrm{C}$. The majority of the gas turbines at the existing operating oxygen-blown IGCC with the cold synthetic gas cleanup process operate according to the similar technique, in this case the gas preheating to the temperature of $\sim 300^{\circ} \mathrm{C}$ is performed in the water heaters. The heating to the higher temperatures (up to $420^{\circ} \mathrm{C}$ ) is performed in case of operation on the enriched blast-furnace gas by means of the booster compressor operation. The implementation of the hot synthetic gas cleanup systems in the newly built IGCC will result in the shift of the present technology application field to the more low calorific gases.

The temperature regimes No 2 (the gas temperature of $300^{\circ} \mathrm{C}, 500^{\circ} \mathrm{C}$ and the air temperature of $400^{\circ} \mathrm{C}, 500^{\circ} \mathrm{C}$ ) and No 3 (the gas temperature of $500^{\circ} \mathrm{C}$ the air temperature of $900^{\circ} \mathrm{C}$ ) hereinafter referred to as $300 / 400,500 / 500$ and $500 / 900$ were used during the calculation of the synthetic gas combustion in the gas turbine combustion chamber.

The exhaust gas flow rate at the combustion chamber outlet was kept constant in all regimes during the calculations. The average exhaust gas temperature is set and maintained at $1400^{\circ} \mathrm{C} \pm 50^{\circ} \mathrm{C}$ constant. The temperature deviation impact was considered by means of the temperature correction. The exhaust gas temperature dependence of the NOx emissions, used for the temperature correction determination, is presented in Figure 1.

The characteristics of the synthetic gas used for determination of correction for the temperature deviation are as follows: $\mathrm{CH}_{4}=0.7 \% ; \mathrm{CO}=22.7 \% ; \mathrm{CO}_{2}=4.78 \% ; \mathrm{H}_{2}=22.7 \%$; $\mathrm{H}_{2} \mathrm{O}=5 \% ; \quad \mathrm{N}_{2}=44 \% ; \quad \mathrm{H}_{2} \mathrm{~S}=0.0015 \% ; \quad \mathrm{NH}_{3}=0.1 \% ; \quad \mathrm{COS}=0.0015 \% ; \quad \mathrm{HCN}=0.003 \%$; $\mathrm{LHV}=5.575 \mathrm{MJ} / \mathrm{nm}^{3} ; \mathrm{H}_{2} / \mathrm{CO}=1$. The correction curve is plotted for the A point conditions (Figure 2).

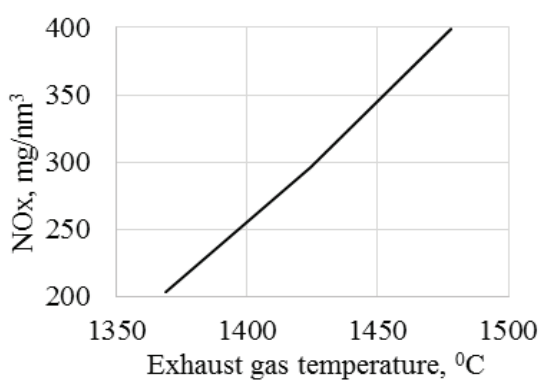

Fig. 1. The exhaust gas temperature dependence of the NOx emissions

During the linearization of the correction curve, presented in Figure 1, the NOx temperature sensitivity was $1.8 \mathrm{mg} /\left(\mathrm{m}^{3} \cdot \mathrm{K}\right)$.

The impact of the combustion regime of the synthetic gases of different LHV on the NOx emissions is presented in Figure 2.

Characteristics for the used synthetic gases (vol.\%): $\mathrm{CH}_{4}=0 \div 0.7 ; \mathrm{CO}=9.8 \div 31.4$; $\mathrm{CO}_{2}=4.8 \div 15.9 ; \mathrm{H}_{2}=7.7 \div 34 ; \mathrm{N}_{2}=42.3 \div 58 ; \mathrm{H}_{2} \mathrm{O}=5 ; \mathrm{H}_{2} \mathrm{~S}=0.0015 ; \mathrm{COS}=0.0015 ; \mathrm{HCN}=0.003$; $\mathrm{NH}_{3}=0.1$.

In the $300 / 400$ regime the decrease in the calorific value from $5-6 \mathrm{MJ} / \mathrm{m}^{3}$ to $4.2 \mathrm{MJ} / \mathrm{m}^{3}$ results in the NOx emissions decrease from $140-185 \mathrm{mg} / \mathrm{m}^{3}$ to $50-60 \mathrm{mg} / \mathrm{m}^{3}$. In this case the emissions are at the standard values level even without the special measures implementation. It can be explained by the decrease in the theoretical value of the synthetic gas combustion temperature, and consequently the decrease in the local temperature 
maximums in the combustion chamber, which are the points of the maximum NOx emissions.

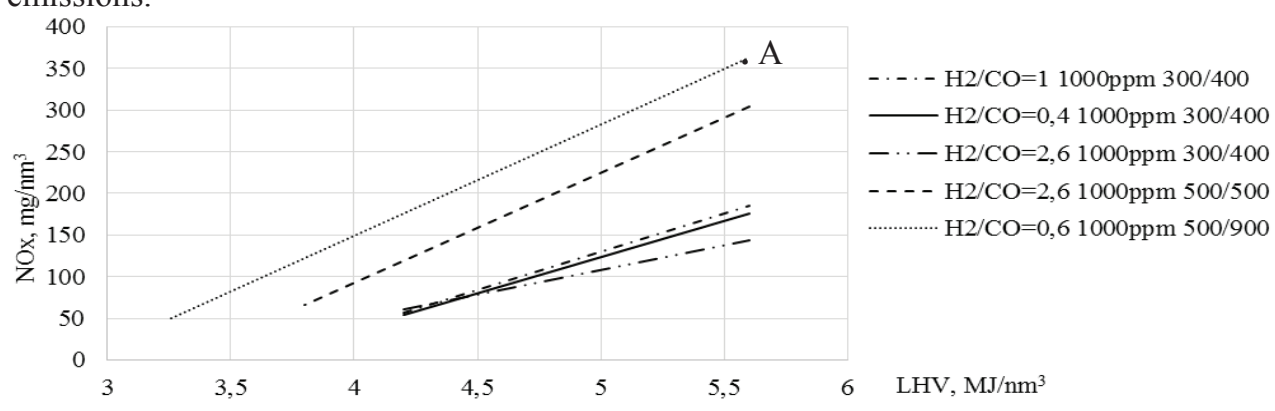

Fig. 2. The impact of the combustion regime of the synthetic gases of different heat capacities on the NOx emissions

In the $300 / 400$ regime the decrease in the calorific value from $5-6 \mathrm{MJ} / \mathrm{m}^{3}$ to $4.2 \mathrm{MJ} / \mathrm{m}^{3}$ results in the NOx emissions decrease from $140-185 \mathrm{mg} / \mathrm{m}^{3}$ to $50-60 \mathrm{mg} / \mathrm{m}^{3}$. In this case the emissions are at the standard values level even without the special measures implementation. It can be explained by the decrease in the theoretical value of the synthetic gas combustion temperature, and consequently the decrease in the local temperature maximums in the combustion chamber, which are the points of the maximum NOx emissions.

Switch from the hot gas combustion in the cycle air (300/400) to the higher temperature regimes (500/500 и 500/900) results in the significant increase in the NOx emissions. However, in case of the low calorific value of the synthetic gas $\left(3.3 \mathrm{MJ} / \mathrm{m}^{3}\right)$, even combustion in the highest temperature regime (500/900) permits to provide the low NOx emissions.

For the hot synthetic gas with the calorific value of $3.2 \mathrm{MJ} / \mathrm{m}^{3}$ in case of the high temperature air heating the presence of ammonia with concentration of $1000 \mathrm{ppm}$ has no sufficient impact on the NOx emissions, which permits to use the synthetic gas uncleaned from ammonia in the gas turbine and exclude the expensive unit of cathalytic cleaning from the nytrogen-bearing impurities from the gas cleanup system.

For the NOx emissions abatement in the regimes with $\mathrm{NOx}>50 \mathrm{mg} / \mathrm{m}^{3}$, the measure widely used by the leading gas turbine manufacturers was taken $[6,7]$, namely the steam supply to the combustion chamber. Usually the steam injection is less than $5 \%$ of the air volume inhausted by the compressor [6]. In case of $\mathrm{NOx}<100 \mathrm{mg} / \mathrm{m}^{3}$ (for dry process) the $5 \%$ condition is met, but if $\mathrm{NOx}>100 \mathrm{mg} / \mathrm{m}^{3}$ the steam injection exceeds $13 \%$ of the exhaust gases flow rate downstream of the combustion chamber. In the lower initial NOx range for dry process $\left(<100 \mathrm{mg} / \mathrm{m}^{3}\right)$, the NOx emissions decreased slowly with the rise in steam injection. The use of the synthetic gas cleaned from ammonia causes slightly reduction of the NOx emissions level, as far as the fuel NOx emissions are reduced. The increase in the $\mathrm{H}_{2} / \mathrm{CO}$ ratio in the fuel gas composition during the steam supply to the combustion chamber results in the increase in the NOx emissions. 


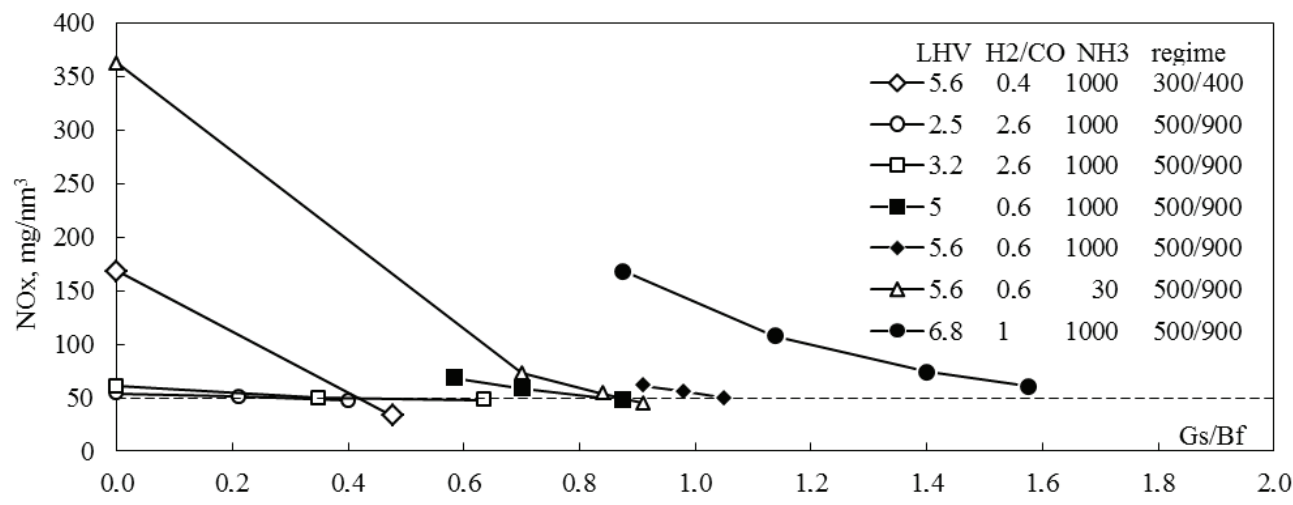

Fig. 3. Dependence of the combustion chamber steam quantity on the NOx emissions. Gs is the steam flow rate, $t / h ; B f$ is the synthes gas flow rate, $t / h$.

General characteristics for the used synthetic gases: $\mathrm{H}_{2} \mathrm{O}=5 \% ; \mathrm{H}_{2} \mathrm{~S}=0.0015 \%$; $\mathrm{COS}=0.0015 \% ; \mathrm{HCN}=0.003 \%$, the distinguishing characteristics are presented in Table 1 .

Table 1. The synthetic gases characteristics

\begin{tabular}{|l|c|c|c|c|c|c|c|}
\hline \multicolumn{1}{|c|}{ № } & 1 & 2 & 3 & 4 & 5 & 6 & 7 \\
\hline $\mathrm{LHV}, \mathrm{MJ} / \mathrm{m}^{3}$ & 5.6 & 2.5 & 3.2 & 4.97 & 5.58 & 6.78 & 5.58 \\
\hline $\mathrm{CH}_{4}$, vol.\% & 0.7 & 0 & 0 & 0.7 & 0.7 & 0.7 & 0.7 \\
\hline $\mathrm{CO}$, vol.\% & 31.4 & 18 & 8 & 27.8 & 27.8 & 27.8 & 27.8 \\
\hline $\mathrm{CO}_{2}$, vol.\% & 4.8 & 20 & 15.9 & 4.8 & 4.8 & 4.8 & 4.8 \\
\hline $\mathrm{H}_{2}$, vol.\% & 12.5 & 2.5 & 20.8 & 16.7 & 16.7 & 27.8 & 11.1 \\
\hline $\mathrm{N}_{2}$, vol.\% & 45.5 & 54.5 & 50.1 & 50.4 & 44.8 & 33.7 & 44.9 \\
\hline $\mathrm{NH}_{3}$, vol.\% & 0.1 & 0.1 & 0.1 & 0.1 & 0.1 & 0.1 & 0.003 \\
\hline
\end{tabular}

\section{Conclusions}

The use of the high temperature air preheating and the hot gas treatment for the low calorific synthetic gas (with the calorific value of $3.3 \mathrm{MJ} / \mathrm{m}^{3}$ ) permits to increase the combustion temperature to the level providing the stable combustion and the NOx emissions value at the standard value. The present technique offers an opportunity for consideration of the synthetic gas application for the turbunes of the temperature class $1700^{\circ} \mathrm{C}$.

This work was carried out at the Ural Federal University and financially supported by the Russian Science Foundation (project no. 14-19-00524).

\section{References}

1. T. Komori, H. Hara, H. Arimura, Y. Kitauchi, Proc. of IGNC, TS-103, 1-8 (2003)

2. T. Hasegawa, Energies, 3, 335-449 (2010)

3. D. Garreton, O. Simonin, ASCF Ercoftac CFD Workshop (1995)

4. H. C. Magel, U. E. Schnell, K. R. G. Hein, Proc. of 26 Symp. On Comb., 67-74 (1996)

5. C. V. da Silva, C. A. Segatto, A. V. de Paula, Proc. of COBEM (2013)

6. S. V. Tsanev, V. D. Burov, A. N. Remezov, Gas turbine power plant and combined cycle power plant, $3^{\text {rd }}$ ed., (2009)

7. K. Tanaka, K. Nishida, W. Akizuki, MHI Tech. Review, 46, 6-12 (2009) 